\title{
EXIGÊNCIAS NUTRICIONAIS DE MUDAS DE Dipteryx alata SOB LIMITAÇÃO NUTRICIONAL
}

\section{NUTRITIONAL REQUIREMENTS OF Dipteryx alata SEEDLINGS GROWN UNDER NUTRIENT- LIMITING CONDITIONS}

\author{
Fabrizio Furtado de Sousa ${ }^{1}$ Rafael Malfitano Braga ${ }^{2}$ Nelson Venturin ${ }^{3}$ Renato Luiz Grisi Macedo ${ }^{4}$ \\ Leandro Carlos ${ }^{5}$ Regis Pereira Venturin ${ }^{6}$
}

\section{RESUMO}

Objetivou-se, neste estudo, avaliar os requerimentos nutricionais e o efeito da limitação de nutrientes no desenvolvimento de mudas de baru (Dipteryx alata Vogel) utilizando a técnica da limitação nutricional. O ensaio foi estabelecido em delineamento inteiramente casualizado com 12 tratamentos e oito repetições. Os tratamentos adotados foram os seguintes: completo $1(\mathrm{Cl}$ - adubado com $\mathrm{N}, \mathrm{P}, \mathrm{K}, \mathrm{S}, \mathrm{B}, \mathrm{Cu}, \mathrm{Zn}$ e calagem), completo 2 (C2 - adubado com N, P, K, S, Ca, Mg, B, Cu, Zn, sem calagem), tratamentos completos com omissão de um nutriente por vez (completo 1 - N, completo 1 - P, completo 1 - K, completo 1 - S, completo 1 - B, completo 1 - Zn, completo 2 - Ca, completo 2 - Mg, completo 1 - calagem) e controle (solo natural). Aferiu-se o diâmetro e a altura das plantas, separando-as em parte aérea e sistema radicular. As mudas foram secas, pesadas, moídas e foi determinado o teor de nutrientes na matéria seca da parte aérea. De acordo com os resultados, as limitações de S e B não afetaram o crescimento das mudas de Dipteryx alata. $\mathrm{P} \mathrm{e} \mathrm{N}$ foram, de forma geral, os nutrientes que mais limitaram o crescimento das mudas de baru. A sequência de exigência nutricional apresentada pelas mudas de baru, considerando a produção de biomassa seca da parte aérea, em ordem decrescente foi: $\mathrm{P}=\mathrm{N}>\mathrm{Ca}=\mathrm{Mg}=\mathrm{Zn}=\mathrm{K}=\mathrm{S}=\mathrm{B}$.

Palavras-chave: nutriente faltante; Fabaceae-Faboideae; Cerrado; adubação mineral.

\begin{abstract}
This study was conducted with the objective of evaluating the nutritional requirements and the effect of nutrient limitation over the development of baru seedlings (Dipteryx alata Vogel), using the nutrient limitation technique. The trial was established in a completely randomized design, with 12 treatments and 8 replicates. The adopted treatments were the following: complete $1(\mathrm{C} 1$ - fertilization with $\mathrm{N}, \mathrm{P}, \mathrm{K}, \mathrm{S}, \mathrm{B}, \mathrm{Cu}$, $\mathrm{Zn}$ and liming), complete 2 (C2 - fertilization with $\mathrm{N}, \mathrm{P}, \mathrm{K}, \mathrm{S}, \mathrm{Ca}, \mathrm{Mg}, \mathrm{B}, \mathrm{Cu}, \mathrm{Zn}$, with no liming), complete treatment with the omission of a nutrient at a time (C1-N, C1-P, C1-K, C1-S, C1-B, C1-Zn, C2-Ca, C2-Mg, C1-liming) and control (natural soil). We assessed plant height and diameter, and separated them into shoot and root system. The seedlings were dried, weighed, ground for the determination of nutrient content of the shoot dry matter. According to the results, the limitation of S and B did not affect the growth of Dipteryx alata seedlings. In general, $\mathrm{P}$ and $\mathrm{N}$ were the nutrients that most limited the growth of Baru seedlings. The

1 Engenheiro Agrônomo, Dr., Professor da Universidade do Estado de Minas Gerais, Av. Paraná, 3001, Jardim Belvedere, CEP 35501-170, Divinópolis (MG), Brasil. fabriziofurtado@gmail.com

2 Engenheiro Florestal, Doutorando do Programa de Pós-graduação em Engenharia Florestal, Departamento de Ciências Florestais, Universidade Federal de Lavras, Caixa Postal 3037, CEP 37200-000, Lavras (MG), Brasil. rafael.malfitano@hotmail.com

3 Engenheiro Florestal, Dr., Professor do Departamento de Ciências Florestais, Universidade Federal de Lavras, Caixa Postal 3037, CEP 37200-000, Lavras (MG), Brasil. venturin@dcf.ufla.br

4 Engenheiro Florestal, Dr., Professor do Departamento de Ciências Florestais, Universidade Federal de Lavras, Caixa Postal 3037, CEP 37200-000, Lavras (MG), Brasil. rlgrisi@dcf.ufla.br

5 Engenheiro Florestal, Dr., Professor do Instituto Federal Goiano, Rodovia Sul Goiana, Km 01, Zona Rural, CEP 75901-970, Rio Verde (GO), Brasil. 1cmaestro@gmail.com

6 Engenheiro Agrônomo, Dr., Pesquisador da Empresa de Pesquisa Agropecuária de Minas Gerais, Caixa Postal 176, CEP 37200-000, Lavras (MG), Brasil. regis@epamig.br
\end{abstract}

Recebido para publicação em 8/04/2015 e aceito em 14/10/2016

Ci. Fl., v. 28, n. 1, jan.- mar., 2018 
sequence of nutritional requirements presented by the Baru seedlings, in decreasing order, considering the production of shoot dry biomass, was: $\mathrm{P}=\mathrm{N}>\mathrm{Ca}=\mathrm{Mg}=\mathrm{Zn}=\mathrm{K}=\mathrm{S}=\mathrm{B}$.

Keywords: missing nutrient; Fabaceae-Faboideae; Cerrado; mineral fertilization.

\section{INTRODUÇÃO}

O bioma Cerrado - com sua grande variabilidade de habitat - é considerado um dos hotspots mundiais de diversidade (MYERS et al., 2000). Estima-se que a sua flora possua aproximadamente 12 mil espécies de plantas (MENDONÇA et al., 2008). As populações regionais utilizam esta flora para as mais diversas finalidades, destacando-se os usos alimentar e medicinal. Diversas espécies medicinais e frutíferas nativas do bioma Cerrado apresentam alto potencial para utilização econômica. No entanto, este bioma vem sofrendo explorações extensivas e predatórias, tornando imprescindível o aprimoramento de tecnologias que possibilitem o uso racional destas áreas e de sua vegetação (ULHÔA, 1997).

Dipteryx alata Vogel, conhecida vulgarmente como baru, cumbaru, barujó, feijão-coco, castanhade-burro, pau-cumaru ou imburana-brava, é uma espécie arbórea da família Fabaceae-Faboideae. Possui altura média de $15 \mathrm{~m}$, podendo alcançar $25 \mathrm{~m}$ em solos férteis, com tronco de 0,40 a $0,70 \mathrm{~m}$ de diâmetro e folhas compostas, alado-pecioladas e glabras (LORENZI, 2008). Os frutos são legumes monospermos e indeiscentes, de polpa seca, com endocarpo lenhoso protegendo a única semente (amêndoa) (LORENZI et al., 2006). É uma árvore perenifólia, heliófila e seletiva xerófita que ocorre nos estados de Minas Gerais, São Paulo, Goiás, Tocantins, Mato Grosso e Mato Grosso do Sul, em solos bem drenados do bioma Cerrado (SANO; RIBEIRO; BRITO, 2004; LORENZI, 2008).

O baru é uma espécie promissora para o cultivo, devido ao seu uso múltiplo, alta taxa de germinação de sementes e de estabelecimento de mudas (SANO; RIBEIRO; BRITO, 2004). A polpa e a semente de baru são energéticas, nutritivas e ricas em minerais com grande potencial para uso na alimentação humana e animal (FREITAS et al., 2012). A polpa é consumida ao natural, bem como na forma de doces e geleias e a amêndoa é consumida in natura ou torrada (LORENZI et al., 2006). Apesar de suas propriedades nutricionais, o baru não é um produto alimentar de rotina, por isso, ele apresenta potencial até mesmo para a produção de biodiesel (BATISTA et al., 2012). Apresenta também o potencial de uso na indústria de medicamentos (ESTEVES-PEDRO et al., 2012) e como madeira para construção (MARTINOTTO et al., 2012). Segundo Heringer (1978), o baru é também uma espécie indicada para a recuperação de áreas degradadas, pois apresenta bom crescimento, baixa exigência de adubação e de manutenção e alta produção de massa foliar. Outra característica que torna o baru uma espécie promissora para o uso em programas de recuperação de áreas degradadas é o fato de ser uma das poucas espécies que apresenta frutos com polpa carnosa durante a estação seca no bioma Cerrado, sendo espécie importante para a alimentação da fauna nessa época (SANO; RIBEIRO; BRITO, 2004).

Dados oficiais sobre a produção e comercialização de baru são escassos. Porém, grande parte desta produção e do comércio baseia-se na extração, o que, se for feito em excesso é prejudicial à conservação da espécie (CRUZ et al., 2011b). Segundo Arakaki et al. (2009), a importância ecológica, econômica e social do baru pode contribuir para a manutenção dos fragmentos florestais remanescentes do Cerrado. Para Vera et al. (2009), estudos que ampliem o conhecimento das espécies do Cerrado podem ajudar na preservação do Bioma, tanto na disponibilização de alternativas de renda pela utilização dos recursos naturais disponíveis, quanto na demonstração dos benefícios nutricionais do fruto, o que justificaria o melhoramento genético das espécies e posterior cultivo econômico. No entanto, pouco ou nada se sabe sobre os aspectos silviculturais do baru, principalmente sobre as suas exigências nutricionais.

O plantio de espécies florestais nativas é uma atividade que, além de repor os recursos florestais, pode atenuar os impactos ambientais decorrentes do extrativismo. Entretanto, o seu sucesso depende, entre outros fatores, do conhecimento acerca das necessidades nutricionais da espécie a ser utilizada (SILVA et al., 2007). Segundo Cruz et al. (2011a), o conhecimento a respeito das espécies florestais nativas é ainda incipiente, sendo, portanto, necessário para uma adequada recomendação da adubação, tendo em vista que as espécies florestais possuem exigências nutricionais diferenciadas.

Segundo Silva et al. (2012), devido à baixa fertilidade da maioria dos solos brasileiros, as práticas 
de calagem e adubação são indispensáveis para fornecer os nutrientes que não estão em concentrações satisfatórias para atender à demanda das plantas nas áreas de reflorestamento.

A técnica do elemento faltante, também conhecida como diagnose por omissão, é uma metodologia usada para a identificação das exigências nutricionais de espécies vegetais. Essa técnica envolve o crescimento de uma planta, sob condições de campo ou casa de vegetação, em que é testado um tratamento completo (com todos os nutrientes) e uma série de tratamentos, nos quais é omitido um nutriente de cada vez (SANCHES; SALINAS, 1981; BRAGA et al., 1995; SILVA; GONÇALVES; PINHO, 2005; SKREBSKY et al., 2008; MORETTI et al., 2011). De acordo com Skrebsky et al. (2008), por meio dessa técnica de diagnose, é possível determinar quais são os nutrientes limitantes ao crescimento e ao estado nutricional das plantas em qualquer tipo de solo. Segundo Malavolta (1980), este método também fornece informações semiquantitativas, relacionadas com os nutrientes que podem limitar o desenvolvimento da planta.

Sendo assim, este trabalho teve por objetivo avaliar os requerimentos nutricionais e o efeito da limitação de nutrientes no crescimento de mudas de Dipteryx alata em casa de vegetação.

\section{MATERIAL E MÉTODOS}

O trabalho foi conduzido em casa de vegetação no Departamento de Ciências Florestais da Universidade Federal de Lavras (UFLA). Utilizou-se, como substrato, uma amostra de Latossolo Vermelho distrófico típico $(\mathrm{LVd})$, de textura muito argilosa, com baixa disponibilidade de nutrientes, coletada no município de Lavras - MG, na camada de $20-40 \mathrm{~cm}$ de profundidade.

Após secagem ao ar livre, o solo foi peneirado e acondicionado em sacos plásticos. Em seguida, foram adicionados os nutrientes, conforme preconizado na técnica da limitação nutricional. Depois de um período de incubação de vinte dias, o solo foi depositado em vasos de polietileno rígido de $5 \mathrm{dm}^{3}$ com fundo vedado, evitando, assim, a drenagem da água e a perda dos nutrientes. Foram retiradas amostras dos tratamentos completo 1 e controle (solo natural) para análises químicas e físicas, cujos resultados encontram-se na Tabela 1.

TABELA 1: Componentes físicos e químicos do solo natural e após adubação com macro e micronutrientes.

TABLE 1: Chemical and physical components of the natural soil and after fertilization with macro and micronutrients.

\begin{tabular}{ccc}
\hline Atributos & Solo não adubado - Natural & Solo após aplicação do tratamento completo 1 \\
\hline $\mathrm{pH}\left(\mathrm{H}_{2} \mathrm{O}\right)$ & 4,8 & 5,7 \\
$\mathrm{P}\left(\mathrm{mg} \mathrm{dm}^{-3}\right)$ & 1,7 & 70,1 \\
$\mathrm{~K}\left(\mathrm{mg} \mathrm{dm}^{-3}\right)$ & 23,0 & 126,0 \\
$\mathrm{Ca}^{2+}\left(\mathrm{cmol}_{\mathrm{c}} \mathrm{dm}^{-3}\right)$ & 0,4 & 1,9 \\
$\mathrm{Mg}^{2+}\left(\mathrm{cmol}_{\mathrm{c}} \mathrm{dm}^{-3}\right)$ & 0,1 & 0,5 \\
$\mathrm{Al}^{3+}\left(\mathrm{cmol}_{\mathrm{c}} \mathrm{dm}^{-3}\right)$ & 0,0 & 0,0 \\
$\mathrm{H}+\mathrm{Al}\left(\mathrm{cmol}_{\mathrm{c}} \mathrm{dm}^{-3}\right)$ & 5,1 & 4,0 \\
$\mathrm{SB}\left(\mathrm{cmol}_{\mathrm{c}} \mathrm{dm}^{-3}\right)$ & 0,6 & 2,7 \\
$(\mathrm{t})\left(\mathrm{cmol}_{\mathrm{c}} \mathrm{dm}^{-3}\right)$ & 0,6 & 2,8 \\
$(\mathrm{~T})\left(\mathrm{cmol}_{\mathrm{c}} \mathrm{dm}^{-3}\right)$ & 5,6 & 6,8 \\
$\mathrm{~V}(\%)$ & 10,0 & 40,2 \\
$\mathrm{~m}(\%)$ & 0,0 & 0,0 \\
$\mathrm{MO}\left(\mathrm{dag} \mathrm{kg}^{-1}\right)$ & 0,5 & 0,5 \\
$\mathrm{Zn}\left(\mathrm{mg} \mathrm{dm}^{-3}\right)$ & 0,3 & 2,7 \\
$\mathrm{Fe}\left(\mathrm{mg} \mathrm{dm}^{-3}\right)$ & 12,6 & 11,2 \\
$\mathrm{Mn}\left(\mathrm{mg} \mathrm{dm}^{-3}\right)$ & 1,8 & 1,8 \\
\hline
\end{tabular}

Continua... 
TABELA 1: Continuação...

TABLE 1: Continued...

\begin{tabular}{ccc}
\hline Atributos & Solo não adubado - Natural & Solo após aplicação do tratamento completo 1 \\
\hline $\mathrm{Cu}\left(\mathrm{mg} \mathrm{dm}^{-3}\right)$ & 0,4 & 2,1 \\
$\mathrm{~B}\left(\mathrm{mg} \mathrm{dm}^{-3}\right)$ & 0,3 & 0,5 \\
$\mathrm{~S}\left(\mathrm{mg} \mathrm{dm}^{-3}\right)$ & 20,7 & 48,5 \\
Areia $\left(\mathrm{dag} \mathrm{kg}^{-1}\right)$ & 16 & - \\
Silte $\left(\mathrm{dag} \mathrm{kg}^{-1}\right)$ & 20 & - \\
Argila $\left(\mathrm{dag} \mathrm{kg}^{-1}\right)$ & 64 & - \\
\hline
\end{tabular}

Em que: $\mathrm{SB}=$ Soma de bases; $\mathrm{t}=$ capacidade de troca de cátions $(\mathrm{CTC})$ efetiva; $\mathrm{T}=\mathrm{CTC}$ potencial; $\mathrm{V} \%=$ Percentagem de saturação de bases; $\mathrm{m}$ = Percentagem de saturação de alumínio; $\mathrm{MO}$ = matéria orgânica.

O delineamento experimental foi o inteiramente casualizado, com 12 tratamentos (Tabela 2) e oito repetições, sendo a unidade experimental constituída por um vaso e uma planta por vaso.

As doses dos nutrientes, para os tratamentos completos, seguiram a recomendação básica proposta por Malavolta (1980) e Raij (1991) para experimentos em casa de vegetação: $100 \mathrm{mg}$ de N, $300 \mathrm{mg}$ de $\mathrm{P}, 100 \mathrm{mg}$ de K, $200 \mathrm{mg}$ de $\mathrm{Ca}, 60 \mathrm{mg}$ de $\mathrm{Mg}, 40 \mathrm{mg}$ de S, 0,5 mg de B, 1,5 mg de Cu, 0,5 mg de Zn. As fontes de nutrientes foram: $\mathrm{NH}_{4} \mathrm{NO}_{3}, \mathrm{H}_{3} \mathrm{PO}_{4}, \mathrm{KH}_{2} \mathrm{PO}_{4}, \mathrm{MgSO}_{4} \cdot 7 \mathrm{H}_{2} \mathrm{O}, \mathrm{CaSO}_{4} \cdot 2 \mathrm{H}_{2} \mathrm{O}, \mathrm{Na}_{2} \mathrm{SO}_{4}, \mathrm{CuSO}_{4} \cdot 5 \mathrm{H}_{2} \mathrm{O}$, $\mathrm{H}_{3} \mathrm{BO}_{3}, \mathrm{ZnCl}_{2}$.

Nos tratamentos com calagem, aplicou-se calcário dolomítico calcinado, micropulverizado, com $36 \%$ de $\mathrm{CaO}$ e $14 \%$ de $\mathrm{MgO}$ (PRNT 100\%). A dose de calcário foi calculada pelo método da saturação por bases, visando a sua elevação a $70 \%$.

No tratamento completo 2, o $\mathrm{Ca}$ e o $\mathrm{Mg}$ foram disponibilizados, respectivamente, na forma de $\mathrm{CaSO}_{4} \cdot 2 \mathrm{H}_{2} \mathrm{O}$ e de $\mathrm{MgSO}_{4} .7 \mathrm{H}_{2} \mathrm{O}$. Procurou-se, assim, fornecer estes nutrientes sem alterar as demais características do solo.

As sementes de Dipteryx alata foram coletadas na região de ocorrência natural da espécie, no Norte do Estado de Minas Gerais, na cidade de Paracatu e região. Após beneficiadas, elas foram germinadas em germinadores e, logo após a protrusão das radículas, trasladadas para vasos na casa de vegetação.

Irrigações diárias foram efetuadas com água desmineralizada, buscando-se manter, por meio de aferições diárias de pesagem, o solo com umidade próxima de $60 \%$ do volume total de poros. Os vasos foram submetidos a rodízio periódico para evitar o efeito de localização na casa de vegetação.

TABELA 2: Identificação e caracterização dos tratamentos.

TABLE 2: Identification and characterization of treatments.

\begin{tabular}{cc}
\hline Tratamento & Caracterização \\
\hline Completo 1 (C1) & Aplicação de N, $, \mathrm{K}, \mathrm{S}, \mathrm{B}, \mathrm{Cu}, \mathrm{Zn}+$ calcário \\
Completo 2 $(\mathrm{C} 2)$ & Completo 1 - calcário $+\mathrm{CaSO}_{4} \cdot 2 \mathrm{H}_{2} \mathrm{O}$ e $\mathrm{MgSO}_{4} \cdot 7 \mathrm{H}_{2} \mathrm{O}$ \\
$\mathrm{C} 1-\mathrm{Cal}$ & Completo 1 - calcário \\
$\mathrm{C} 1-\mathrm{N}$ & Completo 1 e omissão de $\mathrm{N}$ \\
$\mathrm{C} 1-\mathrm{P}$ & Completo 1 e omissão de $\mathrm{P}$ \\
$\mathrm{C} 1-\mathrm{K}$ & Completo 1 e omissão de $\mathrm{K}$ \\
$\mathrm{C} 1-\mathrm{S}$ & Completo 1 e omissão de $\mathrm{S}$ \\
$\mathrm{C} 1-\mathrm{B}$ & Comissão de B \\
$\mathrm{C} 1-\mathrm{Zn}$ & Completo 1 e omissão de $\mathrm{Zn}$ \\
$\mathrm{C} 2-\mathrm{Ca}$ & Completssão de $\mathrm{Ca}$ \\
$\mathrm{C} 2-\mathrm{Mg}$ & Solo omissão de $\mathrm{Mg}$ \\
$\mathrm{Controle}$ &
\end{tabular}


Depois de transcorridos seis meses, período de duração do ensaio, foram avaliados: diâmetro do colo, altura da planta e produção de biomassa seca da parte aérea e das raízes. O diâmetro foi tomado no coleto e a altura, do nível do solo ao meristema da gema apical da planta. Depois de medidos os diâmetros e as alturas, as mudas foram cortadas rente ao solo. O sistema radicular foi separado do solo e lavado. Ambas, raízes e parte aérea, foram secas em estufa com circulação de ar, a $65^{\circ} \mathrm{C}$, até atingir peso constante. Os materiais secos foram pesados obtendo-se as biomassas secas da parte aérea, do sistema radicular e total. Com os valores aferidos, calculou-se o índice de qualidade de mudas de Dickson - IQD (DICKSON; LEAF; HOSNER, 1960).

A biomassa seca da parte aérea foi triturada e, em seguida, utilizada para determinar os teores de macro e micronutrientes, segundo Sarruge e Haag (1974). Foram analisadas três plantas de cada tratamento, com cada planta constituindo uma repetição. O acúmulo de nutrientes, na parte aérea das mudas, foi determinado multiplicando-se o teor de cada nutriente pela biomassa seca da parte aérea.

Os dados obtidos foram submetidos à análise de variância, e as médias dos tratamentos comparadas pelo teste Scott-Knott a 5\% de probabilidade, conforme Gomes (1985). Para tal, foi utilizado o programa Sisvar 5.3 (FERREIRA, 2003).

\section{RESULTADOS E DISCUSSÃO}

\section{Crescimento das plantas}

Para as características altura e diâmetro, os tratamentos com omissão de B e S, bem como os tratamentos completos 1 e 2 foram superiores aos demais tratamentos (Tabela 3 e Figura 1); demonstrando que esta espécie é pouco exigente em B e S. Para o diâmetro, além da omissão de B e S, a omissão de $\mathrm{K}$ também se mostrou indiferente em relação aos tratamentos completos. A semente de Dipteryx alata apresenta alto teor de macro e micronutrientes (VALILLO; TAVARES; AUED, 1990), o que pode ter suprido as necessidades da muda em sua fase inicial de crescimento.

Os nutrientes que mais afetaram o crescimento das plantas de Dipteryx alata em relação aos tratamentos completos, considerando a altura de plantas, em ordem decrescente, foram: $\mathrm{N}=\mathrm{P}=\mathrm{Mg}=\mathrm{Zn}$ $=\mathrm{Ca}=\mathrm{K}>\mathrm{B}=\mathrm{S}$. Porém, Silva (2014) e Vieira (2011), ao avaliarem o efeito da omissão de nutrientes sobre o desenvolvimento de mudas de Dipteryx alata, utilizando a técnica do elemento faltante em solução nutritiva, verificaram que o crescimento em altura da espécie não foi influenciado significativamente pela omissão dos nutrientes.

Apesar de os estudos com Dipteryx alata serem incipientes, diversos autores analisaram a resposta, em altura, de outras espécies nativas à omissão de nutrientes. Deste modo, Duboc et al. (1996a), Souza, Venturin e Macedo (2006) e Venturin et al. (1999a) analisando Copaifera langsdorffii, Handroanthus impetiginosus e Peltophorum dubium verificaram que $\mathrm{N}$ e $\mathrm{P}$ foram os nutrientes mais limitantes ao crescimento em altura das plantas. No entanto, Carlos et al. (2015) estudando Dalbergia nigra, verificaram que o $\mathrm{N}$ foi o elemento menos limitante ao crescimento da espécie. Mas, no mesmo estudo, também, observaram que o $\mathrm{P}$ foi o nutriente que mais limitou o crescimento das plantas, em altura e diâmetro, com médias que não diferiram do tratamento com omissão de $\mathrm{Ca}$.

TABELA 3: Altura (H), diâmetro da altura do colo (D), biomassa seca da parte aérea (BSPA) biomassa seca de raiz (BSR), biomassa seca total (BST), relação raiz/parte aérea (R/PA) e índice de qualidade de mudas de Dickson (IQD) para plantas de Dipteryx alata.

TABLE 3: Height (H), diameter at the root collar height (D), dry weight of shoots (BSPA), dry root biomass (BSR), total dry biomass (BST), relation root/shoots (R/PA), and Dickson Quality Index of Dickson (IQD) of seedlings of Dipteryx alata.

\begin{tabular}{cccccccc}
\hline Tratamento & $\mathrm{H}(\mathrm{cm})$ & $\mathrm{D}(\mathrm{mm})$ & BSPA $(\mathrm{g})$ & BSR $(\mathrm{g})$ & BST $(\mathrm{g})$ & R/PA & IQD \\
\hline Controle & $14,12 \mathrm{~b}$ & $6,56 \mathrm{~b}$ & $4,97 \mathrm{~b}$ & $7,44 \mathrm{a}$ & $12,41 \mathrm{~b}$ & $1,49 \mathrm{a}$ & $4,38 \mathrm{a}$ \\
$\mathrm{C} 1$ & $21,11 \mathrm{a}$ & $7,67 \mathrm{a}$ & $9,01 \mathrm{a}$ & $6,79 \mathrm{a}$ & $15,80 \mathrm{a}$ & $0,75 \mathrm{~b}$ & $3,77 \mathrm{~b}$ \\
$\mathrm{C} 2$ & $21,75 \mathrm{a}$ & $7,92 \mathrm{a}$ & $11,76 \mathrm{a}$ & $9,16 \mathrm{a}$ & $20,92 \mathrm{a}$ & $0,78 \mathrm{~b}$ & $5,22 \mathrm{a}$ \\
\hline
\end{tabular}


TABELA 3: Continuação....

TABLE. 3: Continued...

\begin{tabular}{cccrrrrc}
\hline Tratamento & H $(\mathrm{cm})$ & D $(\mathrm{mm})$ & BSPA $(\mathrm{g})$ & BSR $(\mathrm{g})$ & BST $(\mathrm{g})$ & R/PA & IQD \\
\hline C1-N & $12,26 \mathrm{~b}$ & $6,92 \mathrm{~b}$ & $4,74 \mathrm{~b}$ & $6,47 \mathrm{a}$ & $11,20 \mathrm{~b}$ & $1,37 \mathrm{a}$ & $4,48 \mathrm{a}$ \\
C1-P & $14,69 \mathrm{~b}$ & $7,06 \mathrm{~b}$ & $3,96 \mathrm{~b}$ & $3,33 \mathrm{a}$ & $7,29 \mathrm{~b}$ & $0,84 \mathrm{~b}$ & $2,14 \mathrm{~b}$ \\
C1-K & $17,69 \mathrm{~b}$ & $8,17 \mathrm{a}$ & $9,73 \mathrm{a}$ & $7,22 \mathrm{a}$ & $16,94 \mathrm{a}$ & $0,80 \mathrm{~b}$ & $4,80 \mathrm{a}$ \\
C1-calagem & $16,22 \mathrm{~b}$ & $7,35 \mathrm{~b}$ & $8,34 \mathrm{a}$ & $8,85 \mathrm{a}$ & $17,19 \mathrm{a}$ & $1,09 \mathrm{~b}$ & $5,67 \mathrm{a}$ \\
C2-Ca & $17,51 \mathrm{~b}$ & $6,80 \mathrm{~b}$ & $7,49 \mathrm{a}$ & $5,43 \mathrm{a}$ & $12,92 \mathrm{~b}$ & $0,73 \mathrm{~b}$ & $3,24 \mathrm{~b}$ \\
C2-Mg & $15,62 \mathrm{~b}$ & $6,46 \mathrm{~b}$ & $7,97 \mathrm{a}$ & $6,45 \mathrm{a}$ & $14,42 \mathrm{~b}$ & $0,90 \mathrm{~b}$ & $3,90 \mathrm{~b}$ \\
C1-S & $19,84 \mathrm{a}$ & $7,89 \mathrm{a}$ & $10,07 \mathrm{a}$ & $8,35 \mathrm{a}$ & $18,43 \mathrm{a}$ & $0,91 \mathrm{~b}$ & $4,92 \mathrm{a}$ \\
C1-Zn & $16,74 \mathrm{~b}$ & $6,85 \mathrm{~b}$ & $9,59 \mathrm{a}$ & $6,25 \mathrm{a}$ & $15,85 \mathrm{a}$ & $0,80 \mathrm{~b}$ & $4,10 \mathrm{~b}$ \\
C1-B & $19,83 \mathrm{a}$ & $8,58 \mathrm{a}$ & $10,72 \mathrm{a}$ & $8,92 \mathrm{a}$ & $19,64 \mathrm{a}$ & $0,86 \mathrm{~b}$ & $5,53 \mathrm{a}$ \\
\hline
\end{tabular}

Em que: $\mathrm{C} 1$ = completo 1 (adubado com N, P, K, S, B, Cu, Zn e calagem); C2 = completo 2 (adubado com N, P, K, $\mathrm{S}, \mathrm{Ca}, \mathrm{Mg}, \mathrm{B}, \mathrm{Cu}, \mathrm{Zn}$, sem calagem). Médias seguidas da mesma letra minúscula na coluna, não diferem entre si pelo teste de Scott-Knott a 5\% de probabilidade.

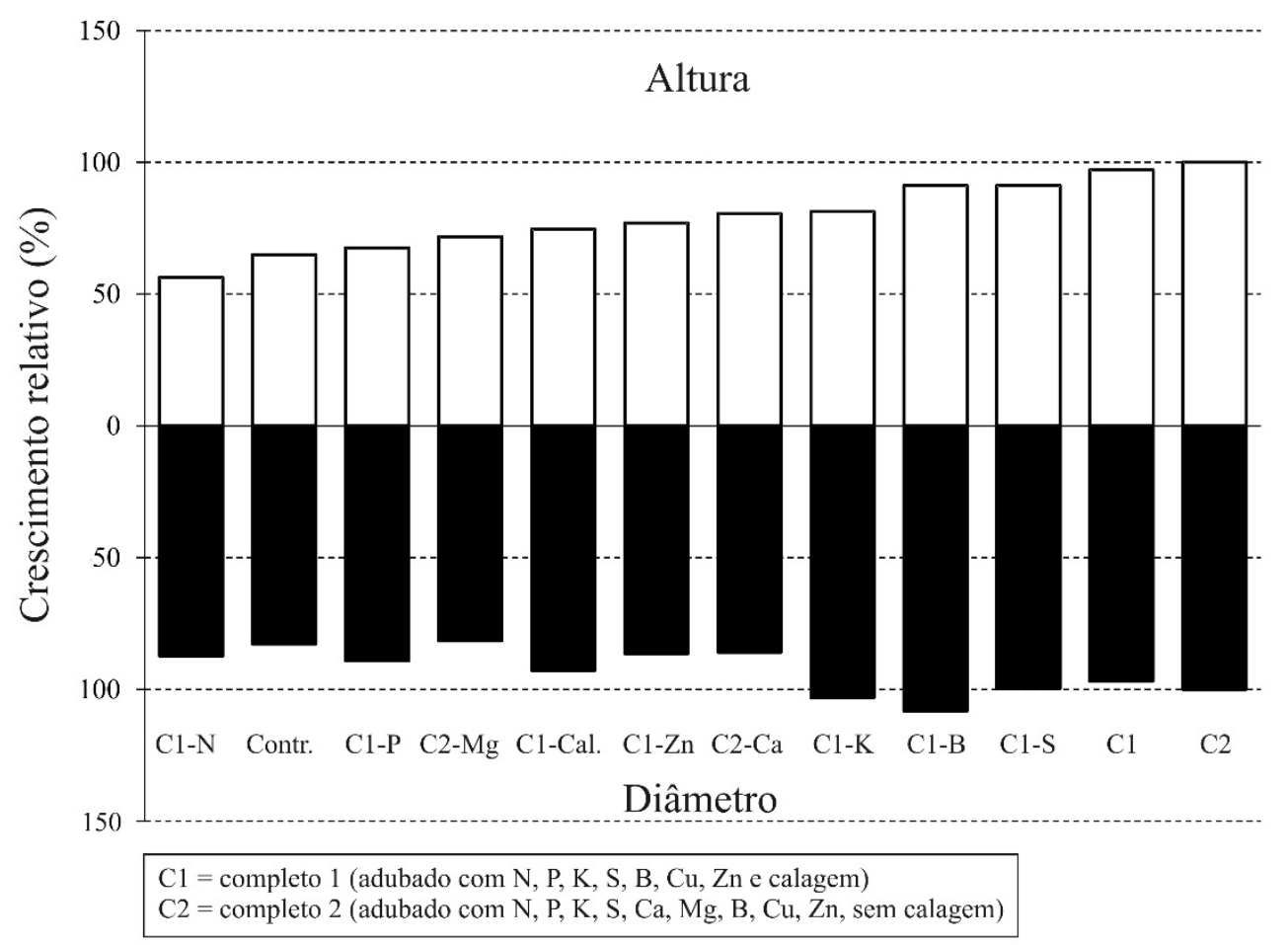

FIGURA 1: Crescimento relativo de mudas de Dipteryx alata em diâmetro e altura.

FIGURE 1: Relative growth of seedlings of Dipteryx alata in diameter and height.

Considerando-se a produção de biomassa seca da parte aérea (BSPA), a sequência de exigência nutricional das mudas de Dipteryx alata, em ordem decrescente, foi: $\mathrm{P}=\mathrm{N}>\mathrm{Ca}=\mathrm{Mg}=\mathrm{Zn}=\mathrm{K}=\mathrm{S}=\mathrm{B}$ (Figura 2). O N, dentre todos os nutrientes, é o que se encontra em maiores concentrações nos vegetais superiores, ele faz parte de proteínas, ácidos nucleicos e muitos outros importantes constituintes celulares. É um dos elementos minerais requeridos em maior quantidade e o que mais limita o crescimento da planta (SOUZA; FERNANDES, 2006). De acordo com Epstein e Bloom (2006), o P possui um papel fundamental na planta, tanto no genoma quanto na aquisição de energia, uma vez que ele é componente essencial dos ácidos nucleicos e de compostos relacionados com a aquisição, estocagem e utilização de energia, como o trifosfato de adenosina. 


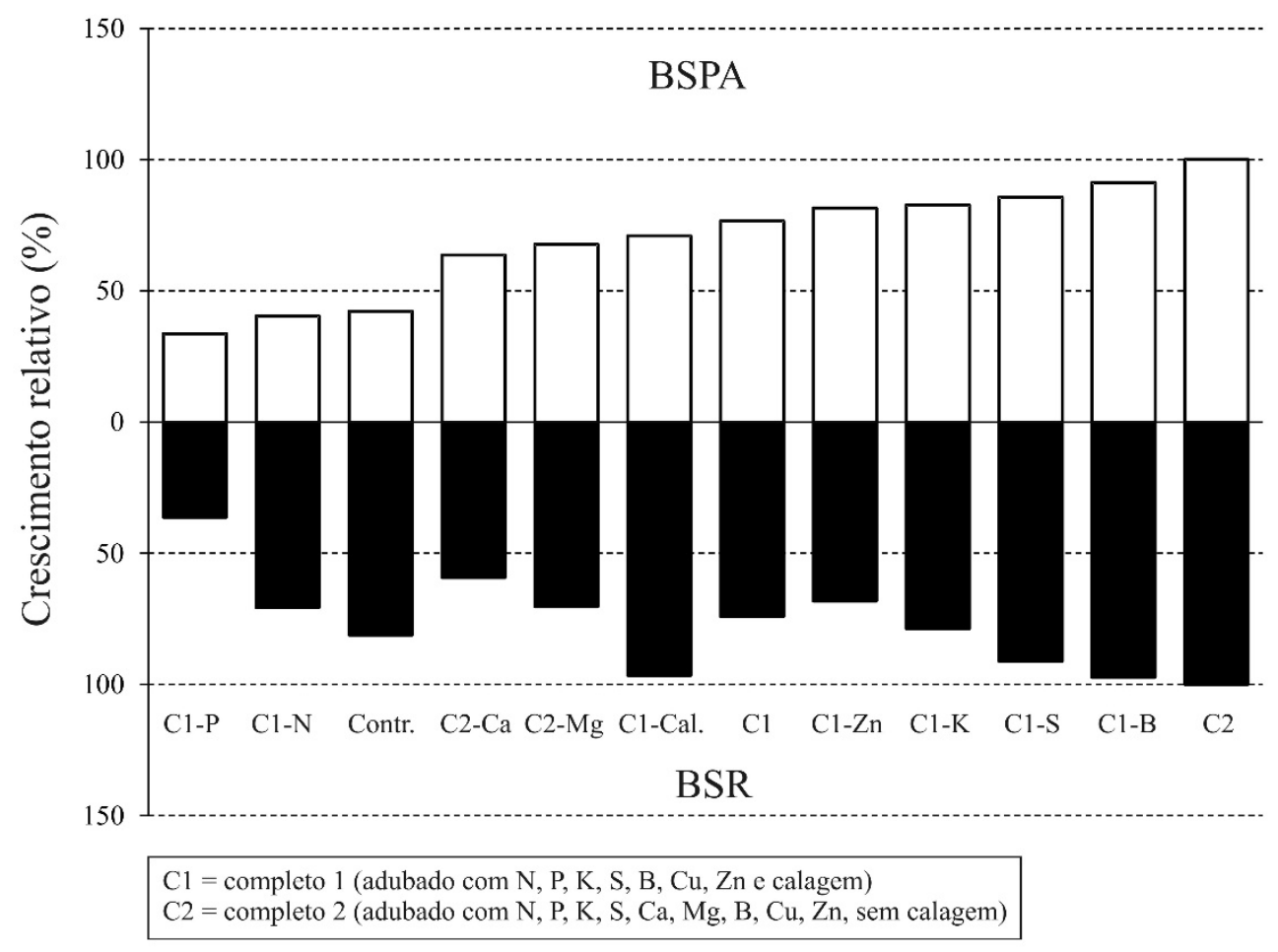

FIGURA 2: Crescimento relativo das mudas de Dipteryx alata em relação à biomassa seca da parte aérea (BSPA) e do sistema radicular (BSR).

FIGURE 2: Relative growth of seedlings of Dipteryx alata in relation to dry biomass of shoots and roots.

A menor produção de BSPA, quando da omissão de N e P, foi também obtida por Souza, Venturin e Macedo (2006) para mudas de Handroanthus impetiginosus e por Silva, Gonçalves e Pinho (2005) para mudas de Spondias tuberosa. No entanto, Vieira (2011), em solução nutritiva, observou que, para Dipteryx alata, a BSPA foi limitada, principalmente, por $\mathrm{K}$ e $\mathrm{Mg}$.

Não foi verificada diferença significativa entre os tratamentos para produção de biomassa seca de raiz (BSR). Contudo, Vieira (2011) avaliando apenas a omissão de macronutrientes, e Silva (2014) avaliando a omissão tanto de macro quanto de micronutrientes, ambos em solução nutritiva, observaram que, para Dipteryx alata, a BSR foi limitada, respectivamente, por $\mathrm{K}, \mathrm{Ca}, \mathrm{Mg}$ e $\mathrm{S}$, e por $\mathrm{Ca}, \mathrm{Mg}, \mathrm{K}, \mathrm{Cu}, \mathrm{Fe}$ e Mn.

Nos ambientes com baixa fertilidade, a relação R/PA é maior (SOUZA; VENTURIN; MACEDO, 2006). Segundo Clarkson (1985), esta é uma estratégia adotada pelas plantas para retirar o máximo de nutrientes dos solos com baixa fertilidade. Os tratamentos que tiveram maior relação R/PA foram o controle e o tratamento com omissão de $\mathrm{N}$. Tratamentos com omissão de $\mathrm{N}$ estão também entre os que tiveram maior relação R/PA em trabalhos desenvolvidos com Copaifera langsdorffii (DUBOC et al., 1996a), Peltophorum dubium (VENTURIN et al., 1999a), Trema micranta (VENTURIN et al., 1999b), Eremanthus erythropappus (VENTURIN et al., 2005) e Handroanthus impetiginosus (SOUZA; VENTURIN; MACEDO, 2006).

O índice de qualidade de mudas de Dickson (IQD) avalia a qualidade da muda. Quanto maior for o IQD, maior é o padrão de qualidade da muda (GOMES, 2001). Os menores valores de IQD foram obtidos em tratamentos com omissão de P, Mg, Zn, Ca e tratamento completo com calagem. Silva (2014) analisando a omissão de nutrientes em Dipteryx alata, em solução nutritiva, encontrou resultados semelhantes, com menor IQD nos tratamentos com omissão dos macronutrientes $\mathrm{Ca}, \mathrm{K} \mathrm{e} \mathrm{Mg}$, bem como dos micronutrientes $\mathrm{Fe}, \mathrm{Mn}, \mathrm{Cu}$ e Mo. 


\section{Nutrição mineral das plantas}

O teor de $\mathrm{N}$ foi maior nos tratamentos com omissão de $\mathrm{P}, \mathrm{K}, \mathrm{Ca}, \mathrm{Mg}, \mathrm{S}$ e $\mathrm{Zn}$, no tratamento completo 2 e no completo 1 sem calagem (Tabela 4). Em relação aos tratamentos com omissão de P, K, Ca, Mg e S, pode-se inferir que este resultado foi devido ao efeito de concentração, pois, quando foi avaliado o acúmulo de $\mathrm{N}$ nestes tratamentos, apenas os tratamentos com omissão de $\mathrm{S}$, completo 2 e completo 1 sem calagem apresentaram elevado acúmulo do elemento. Os menores teores de $\mathrm{N}$ foram observados nos tratamentos completo 1, controle, com omissão de B e do próprio elemento. Diversos estudos com limitação nutricional em espécies florestais também verificaram menor teor de $\mathrm{N}$ nos tratamentos-controle e com omissão de N (DUBOC et al., 1996a; 1996b; VENTURIN et al., 1999a; SILVA; GONÇALVES; PINHO, 2005). De acordo com Dechen e Nachtigall (2006), o B desempenha papel importante no metabolismo do N, o que pode ter ocasionado o baixo teor de $\mathrm{N}$ nas plantas do tratamento com omissão de $\mathrm{B}$.

TABELA 4: Teor de macronutrientes $\left(\mathrm{g} \mathrm{kg}^{-1}\right)$ na biomassa seca da parte aérea (BSPA) de mudas de Dipteryx alata, submetidas ao tratamento com e sem omissão de nutrientes.

TABLE 4: Content of macronutrients in dry biomass of shoots (BSPA) of seedlings of Dipteryx alata under treatment with and without omission of nutrients.

\begin{tabular}{ccccccc}
\hline Tratamento & $\mathrm{N}$ & $\mathrm{P}$ & $\mathrm{K}$ & $\mathrm{Ca}$ & $\mathrm{Mg}$ & $\mathrm{S}$ \\
\hline Controle & $15,03 \mathrm{~b}$ & $0,68 \mathrm{a}$ & $26,77 \mathrm{~b}$ & $18,48 \mathrm{~b}$ & $1,05 \mathrm{c}$ & $1,23 \mathrm{a}$ \\
$\mathrm{C} 1$ & $16,47 \mathrm{~b}$ & $1,15 \mathrm{a}$ & $28,78 \mathrm{a}$ & $18,29 \mathrm{~b}$ & $1,19 \mathrm{c}$ & $0,91 \mathrm{a}$ \\
$\mathrm{C} 2$ & $22,47 \mathrm{a}$ & $1,01 \mathrm{a}$ & $28,60 \mathrm{a}$ & $24,77 \mathrm{a}$ & $1,71 \mathrm{~b}$ & $1,54 \mathrm{a}$ \\
C1-N & $11,10 \mathrm{~b}$ & $1,23 \mathrm{a}$ & $28,05 \mathrm{a}$ & $11,51 \mathrm{~b}$ & $1,40 \mathrm{~b}$ & $0,86 \mathrm{a}$ \\
C1-P & $23,43 \mathrm{a}$ & $0,50 \mathrm{a}$ & $28,78 \mathrm{a}$ & $15,37 \mathrm{~b}$ & $0,97 \mathrm{c}$ & $0,96 \mathrm{a}$ \\
C1-K & $20,90 \mathrm{a}$ & $0,63 \mathrm{a}$ & $24,57 \mathrm{c}$ & $23,75 \mathrm{a}$ & $1,75 \mathrm{~b}$ & $0,85 \mathrm{a}$ \\
C1-calagem & $26,00 \mathrm{a}$ & $0,91 \mathrm{a}$ & $27,87 \mathrm{a}$ & $22,39 \mathrm{a}$ & $1,69 \mathrm{~b}$ & $1,12 \mathrm{a}$ \\
C2-Ca & $20,87 \mathrm{a}$ & $1,24 \mathrm{a}$ & $30,07 \mathrm{a}$ & $18,98 \mathrm{~b}$ & $2,49 \mathrm{a}$ & $1,21 \mathrm{a}$ \\
C2-Mg & $19,83 \mathrm{a}$ & $0,94 \mathrm{a}$ & $28,78 \mathrm{a}$ & $24,12 \mathrm{a}$ & $1,52 \mathrm{~b}$ & $1,13 \mathrm{a}$ \\
C1-S & $22,00 \mathrm{a}$ & $1,62 \mathrm{a}$ & $28,78 \mathrm{a}$ & $23,84 \mathrm{a}$ & $1,32 \mathrm{c}$ & $1,01 \mathrm{a}$ \\
C1-Zn & $20,20 \mathrm{a}$ & $1,39 \mathrm{a}$ & $29,33 \mathrm{a}$ & $15,24 \mathrm{~b}$ & $1,52 \mathrm{~b}$ & $1,09 \mathrm{a}$ \\
C1-B & $17,90 \mathrm{~b}$ & $0,83 \mathrm{a}$ & $28,78 \mathrm{a}$ & $17,24 \mathrm{~b}$ & $1,15 \mathrm{c}$ & $0,91 \mathrm{a}$ \\
\hline
\end{tabular}

Em que: $\mathrm{C} 1$ = completo 1 (adubado com N, P, K, S, B, Cu, Zn e calagem); $\mathrm{C} 2$ = completo 2 (adubado com N, P, K, $\mathrm{S}, \mathrm{Ca}, \mathrm{Mg}, \mathrm{B}, \mathrm{Cu}, \mathrm{Zn}$, sem calagem). Médias seguidas da mesma letra minúscula na coluna, não diferem entre si pelo teste de Scott-Knott a 5\% de probabilidade.

O teor de P (Tabela 4) e o seu acúmulo (Tabela 5) apresentaram os menores valores no tratamento com ausência do elemento, no entanto, não se verificaram diferenças significativas das médias destas características (teor e acúmulo de P) nos tratamentos estudados. Indicando, assim, que a espécie possui mecanismos para se desenvolver bem em ambientes com baixa disponibilidade de fósforo. Resultado semelhante foi relatado para Hymenaea courbaril, por Duboc et al. (1996b), em experimento com nutriente faltante, no qual as limitações nutricionais não afetaram o acúmulo de $\mathrm{P}$.

Todavia, estudos com Tibouchina granulosa, Platycyamus regnellii (BRAGA et al., 1995), Copaifera langsdorffii (DUBOC et al., 1996a), Schizolobium amazonicum (MARQUES et al., 2004), Caryocar brasiliense (CARLOS et al., 2014) e Dalbergia nigra (CARLOS et al., 2015), utilizando a técnica do elemento faltante, verificaram o menor teor de P no tratamento com omissão do elemento.

$\mathrm{O}$ menor teor de $\mathrm{K}$ foi obtido no tratamento com omissão de $\mathrm{K}$, seguido do tratamento-controle. Todos os demais tratamentos tiveram teores de K estatisticamente iguais. Silva (2014) avaliando a omissão de nutrientes em Dipteryx alata, em solução nutritiva, também observou o menor teor de K no tratamento com omissão do elemento. Resultados semelhantes, nos quais os menores teores de $\mathrm{K}$ foram obtidos nos tratamentos com omissão do elemento e controle, também foram verificados em outras espécies: Caryocar brasiliense (CARLOS et al., 2014), Copaifera langsdorffii (DUBOC et al., 1996a), Handroanthus 
impetiginosus (SOUZA; VENTURIN; MACEDO, 2006) e Spondias tuberosa (SILVA; GONÇALVES; PINHO, 2005). No entanto, quando foi analisado o acúmulo de K, observou-se que os maiores acúmulos ocorreram nos tratamentos completo 2 e com omissão de S; com todos os demais tratamentos apresentando acúmulos menores de $\mathrm{K}$.

TABELA 5: Acúmulo de macronutrientes na biomassa seca da parte aérea (BSPA) de mudas de Dipteryx alata submetidas ao tratamento com e sem omissão de nutrientes.

TABLE 5: Accumulation of macronutrients in dry biomass of shoots (BSPA) of seedlings of Dipteryx alata under treatments with and without omission of nutrients.

\begin{tabular}{lccc|ccc}
\hline \multirow{2}{*}{ Tratamento } & \multicolumn{3}{c|}{ g planta $^{-1}$} & \multicolumn{3}{c}{ mg planta $^{-1}$} \\
\cline { 2 - 7 } & $\mathrm{N}$ & $\mathrm{K}$ & $\mathrm{Ca}$ & $\mathrm{P}$ & $\mathrm{Mg}$ & $\mathrm{S}$ \\
\hline Controle & $0,071 \mathrm{~b}$ & $0,125 \mathrm{~b}$ & $0,085 \mathrm{~b}$ & $3,15 \mathrm{a}$ & $5,07 \mathrm{~b}$ & $5,72 \mathrm{c}$ \\
$\mathrm{C} 1$ & $0,132 \mathrm{~b}$ & $0,229 \mathrm{~b}$ & $0,157 \mathrm{~b}$ & $9,20 \mathrm{a}$ & $9,58 \mathrm{~b}$ & $7,34 \mathrm{c}$ \\
$\mathrm{C} 2$ & $0,291 \mathrm{a}$ & $0,377 \mathrm{a}$ & $0,327 \mathrm{a}$ & $13,22 \mathrm{a}$ & $21,54 \mathrm{a}$ & $19,78 \mathrm{a}$ \\
C1-N & $0,045 \mathrm{~b}$ & $0,113 \mathrm{~b}$ & $0,049 \mathrm{~b}$ & $5,84 \mathrm{a}$ & $6,08 \mathrm{~b}$ & $3,71 \mathrm{c}$ \\
C1-P & $0,092 \mathrm{~b}$ & $0,114 \mathrm{~b}$ & $0,060 \mathrm{~b}$ & $1,98 \mathrm{a}$ & $3,76 \mathrm{~b}$ & $3,59 \mathrm{c}$ \\
C1-K & $0,168 \mathrm{~b}$ & $0,194 \mathrm{~b}$ & $0,188 \mathrm{~b}$ & $5,34 \mathrm{a}$ & $13,88 \mathrm{a}$ & $6,82 \mathrm{c}$ \\
C1-calagem & $0,215 \mathrm{a}$ & $0,234 \mathrm{~b}$ & $0,193 \mathrm{~b}$ & $8,58 \mathrm{a}$ & $14,44 \mathrm{a}$ & $9,42 \mathrm{c}$ \\
C2-Ca & $0,151 \mathrm{~b}$ & $0,219 \mathrm{~b}$ & $0,145 \mathrm{~b}$ & $8,74 \mathrm{a}$ & $18,63 \mathrm{a}$ & $8,92 \mathrm{c}$ \\
C2-Mg & $0,156 \mathrm{~b}$ & $0.206 \mathrm{~b}$ & $0,173 \mathrm{~b}$ & $7,50 \mathrm{a}$ & $9,74 \mathrm{~b}$ & $8,21 \mathrm{c}$ \\
C1-S & $0,304 \mathrm{a}$ & $0,401 \mathrm{a}$ & $0,332 \mathrm{a}$ & $22,43 \mathrm{a}$ & $18,20 \mathrm{a}$ & $13,92 \mathrm{~b}$ \\
C1-Zn & $0,140 \mathrm{~b}$ & $0,199 \mathrm{~b}$ & $0,105 \mathrm{~b}$ & $10,34 \mathrm{a}$ & $10,88 \mathrm{~b}$ & $7,45 \mathrm{c}$ \\
C1-B & $0,100 \mathrm{~b}$ & $0,157 \mathrm{~b}$ & $0,093 \mathrm{~b}$ & $5,12 \mathrm{a}$ & $6,18 \mathrm{~b}$ & $5,14 \mathrm{c}$ \\
\hline
\end{tabular}

Em que: $\mathrm{C} 1$ = completo 1 (adubado com N, P, K, S, B, Cu, Zn e calagem); $\mathrm{C} 2$ = completo 2 (adubado com N, P, K,

$\mathrm{S}, \mathrm{Ca}, \mathrm{Mg}, \mathrm{B}, \mathrm{Cu}, \mathrm{Zn}$, sem calagem). Médias seguidas da mesma letra minúscula na coluna não diferem entre si pelo teste de Scott-Knott a 5\% de probabilidade.

O menor teor de $\mathrm{K}$ foi obtido no tratamento com omissão de $\mathrm{K}$, seguido do tratamento-controle. Todos os demais tratamentos tiveram teores de K estatisticamente iguais. Silva (2014) avaliando a omissão de nutrientes em Dipteryx alata, em solução nutritiva, também observou o menor teor de K no tratamento com omissão do elemento. Resultados semelhantes, nos quais os menores teores de $\mathrm{K}$ foram obtidos nos tratamentos com omissão do elemento e controle, também foram verificados em outras espécies: Caryocar brasiliense (CARLOS et al., 2014), Copaifera langsdorffii (DUBOC et al., 1996a), Handroanthus impetiginosus (SOUZA; VENTURIN; MACEDO, 2006) e Spondias tuberosa (SILVA; GONÇALVES; PINHO, 2005). No entanto, quando foi analisado o acúmulo de K, observou-se que os maiores acúmulos ocorreram nos tratamentos completo 2 e com omissão de S; com todos os demais tratamentos apresentando acúmulos menores de $\mathrm{K}$.

$\mathrm{O}$ maior teor de $\mathrm{Ca}$ foi obtido nos tratamentos completo 2, completo 1 sem calagem, com omissão de $\mathrm{K}, \mathrm{Mg}$ e S. Existe um antagonismo entre cátions, em que o aumento da concentração de um cátion no meio pode acarretar redução da absorção de outros cátions (MALAVOLTA; VITTI; OLIVEIRA, 1997). Sendo assim, as plantas sob omissão de $\mathrm{Mg}$ e $\mathrm{K}$ tiveram favorecida a absorção de $\mathrm{Ca}$, possivelmente, devido a não ocorrência desse antagonismo. $\mathrm{O}$ acúmulo de $\mathrm{Ca}$ foi maior no tratamento completo e no tratamento com omissão de $\mathrm{S}$, sendo que, o acúmulo de Ca nos demais tratamentos foi menor e estatisticamente semelhante.

$\mathrm{O}$ maior teor de $\mathrm{Mg}$ foi observado no tratamento com omissão de $\mathrm{Ca}$, o que pode ser explicado pela redução da competição catiônica entre os dois elementos. Os maiores acúmulos de $\mathrm{Mg}$ ocorreram nos tratamentos completo 2, completo 1 sem calagem e com omissão dos nutrientes $\mathrm{Ca}, \mathrm{S}$ e K. De acordo com Vitti, Lima e Cicarone (2006), a taxa de absorção de Mg pode ser afetada pela competição com outros cátions, como $\mathrm{K}^{+}, \mathrm{NH}_{4}^{+}, \mathrm{Ca}^{2+}$ e $\mathrm{Mn}^{2+}$.

Os teores de $\mathrm{S}$ variaram de $0,85 \mathrm{a} 1,54 \mathrm{~g} \mathrm{~kg}^{-1} \mathrm{e}$ foram estatisticamente iguais para todos os tratamentos. Boni et al. (2016) ao analisarem teores foliares deste elemento, em mudas e em árvores adultas de Dipteryx 
alata, ambas obtidas em campo, verificaram teores de $\mathrm{S}$ de 1,6 e de $1,0 \mathrm{~g} \mathrm{~kg}^{-1}$, respectivamente. Indicando, assim, que a espécie é pouco exigente em $\mathrm{S}$, portanto, eficiente para crescer e absorver nutrientes em condições de solo semelhantes a este estudo. $\mathrm{O}$ acúmulo de $\mathrm{S}$ foi maior no tratamento completo 2 , seguido do tratamento com omissão de $\mathrm{S}$. Todos os demais tratamentos apresentaram acúmulo de $\mathrm{S}$ estatisticamente iguais (Tabela 5).

$\mathrm{Na}$ análise dos teores e acúmulos de micronutrientes, verificou-se efeito dos tratamentos apenas para B, Cu e Zn. No entanto, o teor de B e o acúmulo de $\mathrm{Zn}$ não apresentaram diferença significativa (Tabelas 6 e 7).

TABELA 6: Teor de micronutrientes na biomassa seca da parte aérea (BSPA) de mudas de Dipteryx alata submetidas ao tratamento com e sem omissão de nutrientes.

TABLE 6: Content of micronutrient in dry biomass of shoots (BSPA) of seedlings of Dipteryx alata under treatments with and without omission of nutrients.

\begin{tabular}{cccccc}
\hline Tratamento & $\mathrm{B}\left(\mathrm{mg} \mathrm{kg}^{-1}\right)$ & $\mathrm{Cu}\left(\mathrm{mg} \mathrm{kg}^{-1}\right)$ & $\mathrm{Fe}\left(\mathrm{mg} \mathrm{kg}^{-1}\right)$ & $\mathrm{Mn}\left(\mathrm{mg} \mathrm{kg}^{-1}\right)$ & $\mathrm{Zn}\left(\mathrm{mg} \mathrm{kg}^{-1}\right)$ \\
\hline Controle & $42,78 \mathrm{a}$ & $5,40 \mathrm{a}$ & $766,58 \mathrm{a}$ & $56,02 \mathrm{a}$ & $25,62 \mathrm{~b}$ \\
$\mathrm{C} 1$ & $40,38 \mathrm{a}$ & $5,41 \mathrm{a}$ & $183,15 \mathrm{a}$ & $109,50 \mathrm{a}$ & $28,91 \mathrm{~b}$ \\
$\mathrm{C} 2$ & $34,05 \mathrm{a}$ & $6,78 \mathrm{a}$ & $473,99 \mathrm{a}$ & $244,41 \mathrm{a}$ & $46,49 \mathrm{a}$ \\
$\mathrm{C} 1-\mathrm{N}$ & $42,50 \mathrm{a}$ & $3,52 \mathrm{~b}$ & $1.074,53 \mathrm{a}$ & $34,74 \mathrm{a}$ & $26,71 \mathrm{~b}$ \\
$\mathrm{C} 1-\mathrm{P}$ & $42,55 \mathrm{a}$ & $4,46 \mathrm{~b}$ & $507,58 \mathrm{a}$ & $100,55 \mathrm{a}$ & $117,67 \mathrm{a}$ \\
C1-K & $49,35 \mathrm{a}$ & $3,69 \mathrm{~b}$ & $145,34 \mathrm{a}$ & $144,84 \mathrm{a}$ & $24,43 \mathrm{~b}$ \\
C1-calagem & $31,78 \mathrm{a}$ & $4,89 \mathrm{~b}$ & $518,96 \mathrm{a}$ & $303,45 \mathrm{a}$ & $39,14 \mathrm{~b}$ \\
C2-Ca & $35,68 \mathrm{a}$ & $6,52 \mathrm{a}$ & $512,99 \mathrm{a}$ & $164,85 \mathrm{a}$ & $44,30 \mathrm{~b}$ \\
C2-Mg & $42,00 \mathrm{a}$ & $4,55 \mathrm{~b}$ & $331,75 \mathrm{a}$ & $119,83 \mathrm{a}$ & $30,60 \mathrm{~b}$ \\
C1-S & $37,67 \mathrm{a}$ & $5,66 \mathrm{a}$ & $58,98 \mathrm{a}$ & $90,39 \mathrm{a}$ & $31,11 \mathrm{~b}$ \\
C1-Zn & $38,25 \mathrm{a}$ & $6,26 \mathrm{a}$ & $452,10 \mathrm{a}$ & $198,16 \mathrm{a}$ & $74,14 \mathrm{a}$ \\
C1-B & $30,66 \mathrm{a}$ & $4,80 \mathrm{~b}$ & $606,75 \mathrm{a}$ & $159,58 \mathrm{a}$ & $25,95 \mathrm{~b}$
\end{tabular}

Em que: $\mathrm{C} 1$ = completo 1 (adubado com N, P, K, S, B, Cu, Zn e calagem); $\mathrm{C} 2$ = completo 2 (adubado com N, P, K, $\mathrm{S}, \mathrm{Ca}, \mathrm{Mg}, \mathrm{B}, \mathrm{Cu}, \mathrm{Zn}$, sem calagem). Médias seguidas da mesma letra minúscula na coluna não diferem entre si pelo teste de Scott-Knott a 5\% de probabilidade.

Os teores de B nos tratamentos oscilaram entre 30,66 e 49,35 $\mathrm{mg} \mathrm{kg}^{-1}$. Concentrações de B entre 30 e $50 \mathrm{mg} \mathrm{kg}^{-1}$ de matéria seca do tecido são consideradas como adequadas para um crescimento normal das plantas (DECHEN; NACHTIGALL, 2006). Os tratamentos que apresentaram maior acúmulo de B foram o completo 2 e os tratamentos com omissão de K e S (Tabela 7). Para Copaifera langsdorffii (DUBOC et al., 1996a) e Eremanthus erythropappus (VENTURIN et al., 2005) o maior teor de B foi obtido no tratamento com omissão de N; para Handroanthus impetiginosus foi nos tratamentos com omissão de N e K (SOUZA; VENTURIN; MACEDO, 2006); e para Peltophorum dubium foi nos tratamentos com omissão de N, P e S (VENTURIN et al., 1999a).

$\mathrm{O}$ teor de $\mathrm{Cu}$ foi maior nos tratamentos com omissão de $\mathrm{Ca}, \mathrm{S}$ e $\mathrm{Zn}$ e nos completos 1 e 2 . No entanto, Silva (2014) estudou a omissão de nutrientes em Dipteryx alata, em solução nutritiva e verificou que os tratamentos completos e com omissão dos elementos $\mathrm{K}$, Fe e Mn foram os que proporcionaram maiores teores de $\mathrm{Cu}$. Os maiores acúmulos de $\mathrm{Cu}$ foram observados nos tratamentos completo 2 e com omissão de S. Em seu estudo, Silva (2014) observou maiores acúmulos de Cu nos tratamentos completo e com omissão de $\mathrm{S}$, assim como nos tratamentos com omissão de B e Mn.

Não ocorreu diferença estatística significativa entre os tratamentos para o teor e o acúmulo dos nutrientes $\mathrm{Mn}$ e Fe. Os teores de Mn nos tratamentos oscilaram entre 56,02 e 303,45 mg kg-1 de BSPA e os de Fe entre 58,98 e 1074,53 $\mathrm{mg} \mathrm{kg}^{-1}$ de BSPA. De acordo com Dechen e Nachtigall (2006), concentrações de $\mathrm{Mn}$ entre 20 e 500 e de Fe entre 50 e $100 \mathrm{mg} \mathrm{kg}^{-1}$ de matéria seca do tecido são consideradas como adequadas para um crescimento normal das plantas. 
TABELA 7: Acúmulo de micronutrientes na biomassa seca da parte aérea (BSPA) de mudas de Dipteryx alata submetidas ao tratamento com e sem omissão de nutrientes.

TABLE 7: Accumulation of micronutrients in dry biomass of shoots (BSPA) of seedlings of Dipteryx alata under treatments with and without omission of nutrients.

\begin{tabular}{cccccc}
\hline \multirow{2}{*}{ Tratamento } & \multicolumn{4}{c}{ Acúmulo mg planta $^{-1}$} \\
& $\mathrm{~B}$ & $\mathrm{Cu}$ & $\mathrm{Fe}$ & $\mathrm{Mn}$ & $\mathrm{Zn}$ \\
\hline Controle & $0,191 \mathrm{~b}$ & $0,025 \mathrm{~b}$ & $2,697 \mathrm{a}$ & $0,256 \mathrm{a}$ & $0,119 \mathrm{a}$ \\
C1 & $0,324 \mathrm{~b}$ & $0,043 \mathrm{~b}$ & $1,546 \mathrm{a}$ & $0,772 \mathrm{a}$ & $0,228 \mathrm{a}$ \\
C2 & $0,451 \mathrm{a}$ & $0,090 \mathrm{a}$ & $6,033 \mathrm{a}$ & $3,139 \mathrm{a}$ & $0,616 \mathrm{a}$ \\
C1-N & $0,178 \mathrm{~b}$ & $0,015 \mathrm{~b}$ & $4,219 \mathrm{a}$ & $0,138 \mathrm{a}$ & $0,117 \mathrm{a}$ \\
C1-P & $0,167 \mathrm{~b}$ & $0,018 \mathrm{~b}$ & $2,063 \mathrm{a}$ & $0,397 \mathrm{a}$ & $0,462 \mathrm{a}$ \\
C1-K & $0,399 \mathrm{a}$ & $0,030 \mathrm{~b}$ & $1,199 \mathrm{a}$ & $1,243 \mathrm{a}$ & $0,207 \mathrm{a}$ \\
C1-calagem & $0,262 \mathrm{~b}$ & $0,044 \mathrm{~b}$ & $4,461 \mathrm{a}$ & $2,710 \mathrm{a}$ & $0,329 \mathrm{a}$ \\
C2-Ca & $0,263 \mathrm{~b}$ & $0,047 \mathrm{~b}$ & $3,592 \mathrm{a}$ & $1,359 \mathrm{a}$ & $0,332 \mathrm{a}$ \\
C2-Mg & $0,286 \mathrm{~b}$ & $0,034 \mathrm{~b}$ & $3,483 \mathrm{a}$ & $1,211 \mathrm{a}$ & $0,239 \mathrm{a}$ \\
C1-S & $0,530 \mathrm{a}$ & $0,079 \mathrm{a}$ & $0,776 \mathrm{a}$ & $1,291 \mathrm{a}$ & $0,435 \mathrm{a}$ \\
C1-Zn & $0,251 \mathrm{~b}$ & $0,044 \mathrm{~b}$ & $3,424 \mathrm{a}$ & $1,329 \mathrm{a}$ & $0,461 \mathrm{a}$ \\
C1-B & $0,163 \mathrm{~b}$ & $0,028 \mathrm{~b}$ & $2,688 \mathrm{a}$ & $1,063 \mathrm{a}$ & $0,144 \mathrm{a}$
\end{tabular}

Em que: $\mathrm{C} 1$ = completo 1 (adubado com N, P, K, S, B, Cu, Zn e calagem); $\mathrm{C} 2$ = completo 2 (adubado com N, P, K, $\mathrm{S}, \mathrm{Ca}, \mathrm{Mg}, \mathrm{B}, \mathrm{Cu}, \mathrm{Zn}$, sem calagem). Médias seguidas da mesma letra minúscula na coluna não diferem entre si pelo teste de Scott-Knott a 5\% de probabilidade.

O maior teor de $\mathrm{Zn}$ foi obtido no tratamento com omissão de $\mathrm{P}$, não diferindo estatisticamente dos tratamentos completo 2 e com omissão de Zn. No entanto, Silva (2014), em estudo com omissão de nutrientes em solução nutritiva, não verificou diferença significativa entre os teores de $\mathrm{Zn}$ das mudas de Dipteryx alata. Os teores de $\mathrm{Zn}$ variaram de 24,43 a $117,67 \mathrm{mg} \mathrm{kg}^{-1}$, contudo, em campo, foram relatados teores foliares de $\mathrm{Zn}$ inferiores a estes, tanto em mudas $\left(23,0 \mathrm{mg} \mathrm{kg}^{-1}\right)$ quanto em árvores adultas $(23,5$ $\mathrm{mg} \mathrm{kg}^{-1}$ ) de Dipteryx alata (BONI et al., 2016). O acúmulo de $\mathrm{Zn}$ foi estatisticamente igual em todos os tratamentos. Já Silva (2014) observou maior acúmulo de Zn nos tratamentos completo e com omissão dos elementos Mg, S, B, Mn e Mo.

\section{CONCLUSÕES}

Dipteryx alata apresenta baixo requerimento de B e S. P e $\mathrm{N}$ foram os nutrientes que mais limitaram o crescimento da espécie estudada. A exigência nutricional obtida para Dipteryx alata, considerando-se a produção de biomassa seca da parte aérea, em ordem decrescente, foi: $\mathrm{P}=\mathrm{N}>\mathrm{Ca}=\mathrm{Mg}=\mathrm{Zn}=\mathrm{K}=\mathrm{S}=\mathrm{B}$.

\section{REFERÊNCIAS}

ARAKAKI, A. H. et al. O baru (Dipteryx alata Vog.) como alternativa de sustentabilidade em área de fragmento florestal do Cerrado, no Mato Grosso do Sul. Interações, Campo Grande, v. 10, n. 1, p. 31-39, jan./jun. 2009.

BATISTA, A. C. F. et al. Use of baru oil (Dipteryx alata Vog.) to produce biodiesel and study of the physical and chemical characteristics of biodiesel/petroleum diesel fuel blends. Chemistry and Technology of Fuels and Oils, New York, v. 48, n. 1, p. 13-16, mar. 2012.

BONI, T. S. et al. Avaliação comparativa do estado nutricional de mudas de baru (Dipteryx alata). Ciência Florestal, Santa Maria, v. 26, n. 1, p. 109-121, jan./mar. 2016.

BRAGA, F. A. et al. Requerimentos nutricionais de quatro espécies florestais. Revista Árvore, Viçosa, MG, v. 19, n. 1, p. 18-32, 1995.

CARLOS, L. et al. Crescimento e nutrição mineral de mudas de pequi sob efeito da omissão de nutrientes 
Ciência Florestal, Santa Maria, v. 24, n. 1, p. 13-21, jan./mar. 2014.

CARLOS, L. et al. Growth and mineral nutrition in seedlings of jacarandá-da-bahia subjected to nutrient deprivation. Floresta, Curitiba, v. 45, n. 1, p. 107-116, jan./mar. 2015.

CLARKSON, D. T. Adaptações morfológicas e fisiológicas das plantas a ambientes de baixa fertilidade. In: SIMPÓSIO SOBRE RECICLAGEM DE NUTRIENTES E AGRICULTURA DE BAIXOS INSUMOS NOS TRÓPICOS, 1984, Ilhéus. Anais... Ilhéus: CEPLAC; SBCS, 1985. p. 45-75.

CRUZ, C. A. F. et al. Efeito de macronutrientes sobre o crescimento e qualidade de mudas de canafístula cultivadas em Latossolo Vermelho-Amarelo distrófico. Revista Árvore, Viçosa, MG, v. 35, n. 5, p. 983 995, set./out. 2011a.

CRUZ, K. S. D. et al. Partial characterization of proteins from baru (Dipteryx alata Vog) seeds. Journal of the Science of Food and Agriculture, Oxford, v. 91, n. 11, p. 2006-2012, aug. 2011b.

DECHEN, A. R.; NACHTIGALL, G. R. Micronutrientes. In: FERNANDES, M. S. (Ed.). Nutrição mineral de plantas. Viçosa, MG: Sociedade Brasileira de Ciência do Solo, 2006. p. 327-354.

DICKSON, A.; LEAF, A.; HOSNER, J. F. Quality appraisal of white spruce and white pine seedling stock in nurseries. The Forestry Chronicle, Mattawa, v. 36, n. 1, p. 10-13, 1960.

DUBOC, E. et al. Fertilização de plântulas de Copaifera langsdorffii Desf. (óleo copaíba). Cerne, Lavras, v. 2, n. 2, p. 31-47, 1996a.

DUBOC, E. et al. Nutrição do jatobá (Hymenaea courbaril L. var. stilbocarpa (Hayne) Lee et Lang.). Cerne, Lavras, v. 2, n. 1, p. 138-152, 1996 b.

EPSTEIN, E.; BLOOM, A. J. Nutrição mineral de plantas: princípios e perspectivas. 2. ed. Londrina: Planta, 2006. 403 p.

ESTEVES-PEDRO, N. M. et al. In vitro and in vivo safety evaluation of Dipteryx alata Vogel extract. BMC Complementary and Alternative Medicine, London, v. 12, n. 9, p. 1-9, feb. 2012.

FERREIRA, D. F. SISVAR software: versão 5.3. Lavras: Editora da UFLA, 2003.

FREITAS, J. B. et al. Edible seeds and nuts grown in Brazil as sources of protein for human nutrition. Food and Nutrition Sciences, Wuhan, v. 3, n. 6, p. 857-862, jun. 2012.

GOMES, F. P. Curso de estatística experimental. 2. ed. São Paulo: Nobel, 1985. 466 p.

GOMES, J. M. Parâmetros morfológicos na avaliação da qualidade de mudas de Eucaliptus grandis, produzidas em diferentes tamanhos de tubetes e de dosagens de NPK. 2001. 126 f. Tese (Doutorado em Ciência Florestal) - Universidade Federal de Viçosa, Viçosa, MG, 2001.

HERINGER, E. P. Comportamento de algumas espécies euxiloforas, quando cultivadas no cerrado de Brasília de sementes procedentes de outras regiões fitogeográficas brasileiras. In: CONGRESSO LATINOAMERICANO DE BOTÂNICA, 2.; CONGRESSO BRASILEIRO DE BOTÂNICA, 29., 1978, Brasília; Goiânia. Resumos... Brasília; Goiânia: Sociedade Botânica do Brasil, 1978. p. 56-57.

LORENZI, H. Árvores brasileiras: manual de identificação e cultivo de plantas arbóreas do Brasil. 5. ed. Nova Odessa: Instituto Plantarum, 2008. v. 1. 384 p.

LORENZI, H. et al. Frutas brasileiras e exóticas cultivadas: de consumo in natura. Nova Odessa: Instituto Plantarum, 2006. $672 \mathrm{p}$.

MALAVOLTA, E. Elementos de nutrição mineral de plantas. São Paulo: Ceres, 1980. 251 p.

MALAVOLTA, E.; VITTI, G.C.; OLIVEIRA, S.A. Avaliação do estado nutricional das plantas: princípios e aplicações. 2. ed. Piracicaba: POTAFOS, 1997. 319 p.

MARQUES, P. E. M. et al. Crescimento inicial do paricá (Schizolobium amazonicum) sob omissão de nutrientes e de sódio em solução nutritiva. Cerne, Lavras, v. 10, n. 2, p. 184-195, jul./dez. 2004.

MARTINOTTO, F. et al. Sobrevivência e crescimento inicial de espécies arbóreas nativas do Cerrado em consórcio com mandioca. Pesquisa Agropecuária Brasileira, Brasília, v. 47, n. 1, p. 22-29, jan. 2012.

MENDONÇA, R. C. et al. Flora vascular do Bioma Cerrado: checklist com 12.356 espécies. In: SANO, S. M.; ALMEIDA, S. P.; RIBEIRO, J. F. (Ed.). Cerrado: ecologia e flora. Brasília: Embrapa Cerrados, 2008. v. 2. p. 423-442.

MORETTI, B. D. et al. Growth and mineral nutrition in seedlings of australian cedar (Toona ciliata) subjected to nutrient deprivation. Cerne, Lavras, v. 17, n. 4, p. 453-463, out./dez. 2011.

MYERS, N. et al. Biodiversity hotspots for conservation priorities. Nature, London, v. 403, n. 6772, p. $853-858$, feb. 2000 . 
RAIJ, B. V. Fertilidade do solo e adubação. São Paulo: Associação Brasileira para Pesquisa da Potassa e do Fosfato; Agronômica Ceres, 1991. 343 p.

SANCHEZ, P. A.; SALINAS, J. G. Low-input technology for managing oxisols and ultisols in tropical America. Advances in Agronomy, Madison, v. 34, p. 279-406, 1981.

SANO, S. M.; RIBEIRO, J. F.; BRITO, M. A. Baru: biologia e uso. Planaltina: Embrapa Cerrado, 2004. 54 p. (Embrapa Cerrados. Documentos, 116).

SARRUGE, J. R.; HAAG, H. P. Análises químicas em plantas. Piracicaba: ESALQ, 1974. 56 p.

SILVA, A. et al. avaliação dos efeitos da aplicação de basalto moído na fertilidade do solo e nutrição de Eucalyptus benthamii. Floresta, Curitiba, v. 42, n. 1, p. 69-76, jan./mar. 2012.

SILVA, D. S. N. Nutrição mineral do Baru (Dipteryx alata Vogel) em solução nutritiva: calagem e adubação fosfatada no campo. 2014. 89 f. Dissertação (Mestrado em Engenharia Florestal) - Universidade Federal de Lavras, Lavras, 2014.

SILVA, E. B.; GONÇALVES, N. P.; PINHO, P. J. Limitações nutricionais para crescimento de mudas de umbuzeiro em latossolo vermelho distrófico no Norte de Minas. Acta Scientiarum Agronomy, Maringá, v. 27, n. 1, p. 55-59, jan./mar. 2005.

SILVA, W. G. et al. Effect of micronutrients in oxisoil in the growth of seedling mahogany (Swietenia Macrophilla King). Acta Amazonica, Manaus, v. 37, n. 3, p. 371-376, 2007.

SKREBSKY, E. C. et al. Caracterização das exigências nutricionais de mudas de Pfaffia glomerata em Argissolo Vermelho distrófico arênico pela técnica do nutriente faltante. Ciência Rural, Santa Maria, v. 38, n. 4, p. 989-996, jul. 2008.

SOUZA, P. A.; VENTURIN, N.; MACEDO, R. L. G. Adubação mineral do ipê-roxo (Tabebuia impetiginosa) Ciência Florestal, Santa Maria, v. 16, n. 3, p. 261-270, 2006.

SOUZA, S. R.; FERNANDES, M. S. Nitrogênio. In: FERNANDES, M. S. (Ed.). Nutrição mineral de plantas. Viçosa, MG: Sociedade Brasileira de Ciência do Solo, 2006. p. 216-252.

ULHÔA, M. L. Efeitos da calagem e adubação fosfatada no crescimento inicial e nutrição de plantas de baru (Dipteryx alata Vog.), fruta-de-lobo (Solanum lycocarpum St. Hil) e tingui (Magonia pubescens St. Hil). 1997. 74 f. Dissertação (Mestrado em Engenharia Florestal) - Universidade Federal de Lavras, Lavras, 1997.

VALILLO, M. I.; TAVARES, M.; AUED, S. Composição química da polpa e da semente do fruto de cumbaru (Dipteryx alata Vog.). Caracterização do óleo e da semente. Revista do Instituto Florestal, São Paulo, v. 2, n. 2, p. 115-125, dez. 1990.

VENTURIN, N. et al. Adubação mineral da candeia (Eremanthus erythropapus (DC.) Mcleish). Floresta, Curitiba, v. 35, n. 2, p. 211-219, maio/ago. 2005.

VENTURIN, N. et al. Adubação mineral do angico-amarelo (Peltophorum dubium (Spreng.) Taub.). Pesquisa Agropecuária Brasileira, Brasília, v. 34, n. 3, p. 441-448, mar. 1999a.

VENTURIN, N. et al. Avaliação nutricional da candiúva (Trema micrantha L. Blumes) em casa de vegetação. Floresta, Curitiba, v. 29, n. 1/2, p. 15-26, 1999b.

VERA, R. et al. Características químicas de amêndoas de barueiros (Dipteryx alata Vog.) de ocorrência natural no cerrado do estado de Goiás, Brasil. Revista Brasileira de Fruticultura, Jaboticabal, v. 31, n. 1, p. 112-118, mar. 2009.

VIEIRA, C. R. Crescimento inicial de espécies florestais na omissão de macronutrientes. 2011. $61 \mathrm{f}$. Dissertação (Mestrado em Ciências Florestais e Ambientais) - Faculdade de Engenharia Florestal, Universidade Federal de Mato Grosso, Cuiabá, 2011.

VITTI, G. C.; LIMA, E.; CICARONE, F. Cálcio, magnésio e enxofre. In: FERNANDES, M. S. (Ed.). Nutrição mineral de plantas. Viçosa, MG: Sociedade Brasileira de Ciência do Solo, 2006. p. 299-325. 